$$
\begin{array}{r}
\text { Pontifícia Universidade Católica } \\
\text { do Rio de Janeiro }
\end{array}
$$

\title{
A ironia como estratégia narrativa: uma análise do Regresso Adiado de Manuel Rui
}

Dissertação apresentada como requisito parcial para obtenção do grau de Mestre pelo Programa de PósGraduação em Letras do Departamento de Letras do Centro de Teologia e Ciências Humanas da PUC-Rio.

Professor Orientador Alexandre Montaury 


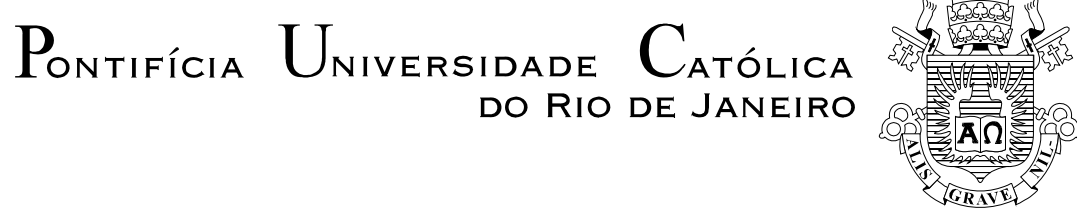

Jarcélen Thaís Teixeira Ribeiro

\section{A ironia como estratégia narrativa: uma análise do Regresso Adiado de Manuel Rui}

Dissertação apresentada como requisito parcial para obtenção do grau de Mestre pelo Programa de PósGraduação em Letras do Departamento de Letras do Centro de Teologia e Ciências Humanas da PUC-Rio. Aprovada pela Comissão Examinadora abaixo assinada.

Prof. Alexandre Montaury Baptista Coutinho

Orientador

Departamento de Letras - PUC-Rio

Prof. Biagio D'Angelo

PUC-SP

Profa. Izabel Margato

Departamento de Letras - PUC-Rio

Prof. Paulo Fernando Carneiro de Andrade

Coordenador Setorial do Centro de Teologia

e Ciências Humanas - PUC-Rio

Rio de Janeiro, 2 de abril de 2009. 
Todos os direitos reservados. É proibida a reprodução total ou parcial do trabalho sem autorização da autora, do orientador e da universidade.

\section{Jarcélen Thaís Teixeira Ribeiro}

Graduou-se em Letras (Português / Literaturas de Língua Portuguesa - Bacharelado e Licenciatura) pela Universidade Federal do Rio de Janeiro em 2005 e especializou-se em Literatura Brasileira (Mediações entre Literatura e Cultura) pela Universidade Católica do Rio de Janeiro em 2007.

Ficha catalográfica

Ribeiro, Jarcélen Thaís Teixeira

A ironia como estratégia narrativa: uma análise do regresso adiado de Manuel Rui / Jarcélen Thaís Teixeira Ribeiro ; orientador: Alexandre Montaury. - 2009.

65 f. ; $30 \mathrm{~cm}$

Dissertação (Mestrado em Letras)-Pontifícia Universidade Católica do Rio de Janeiro, Rio de Janeiro, 2009.

Inclui bibliografia

1. Letras - Teses. 2. Manuel Rui. 3. Literatura angolana. 4. Colonialismo português. 5. Ironia. 6. Papel do intelectual. I. Montaury, Alexandre. II. Pontifícia Universidade Católica do Rio de Janeiro. Departamento de Letras. III. Título.

CDD: 800 


\section{Agradecimentos}

Ao meu orientador Alexandre Montaury, pelo profissionalismo e competência com que conduziu as atividades de orientação.

Ao CNPq e à PUC-Rio, pelos auxílios concedidos, sem os quais o curso de Mestrado não poderia ter sido realizado.

Aos professores Biagio D’Angelo e Izabel Margato, por terem aceitado o convite para participar da banca que avaliou este trabalho.

Aos professores e colegas do Curso de Mestrado em Letras.

A Deus, minha família e amigos, por tudo.

A Raquel, Juliana e Márcia, amigas a quem nada que eu dissesse seria suficiente. 


\section{Resumo}

Ribeiro, Jarcélen Thaís Teixeira; Montaury, Alexandre. A ironia como estratégia narrativa: uma análise de Regresso Adiado, de Manuel Rui. Rio de Janeiro, 2009. 65 p. Dissertação de Mestrado - Departamento de Letras, Pontifícia Universidade Católica do Rio de Janeiro.

Esta dissertação tem como objetivo ler e analisar textos do escritor angolano Manuel Rui, visando mapear o posicionamento do escritor no âmbito das relações coloniais entre Portugal e Angola. A partir do conceito de ironia, tomado como recurso de leitura e de escrita nos textos do autor, proponho o desenvolvimento de uma leitura que contemple um dos recursos centrais na construção de sua obra. Tomando a "ironia" como objeto de estudo e como um dos principais operadores de sentido presentes nas narrativas de Regresso Adiado (1974), esta dissertação é o resultado de uma pesquisa que se estende para a literatura produzida durante os anos de conflito que antecederam a independência em Angola.

\section{Palavras-chave}

Manuel Rui; literatura angolana; colonialismo português; ironia; papel do intelectual. 


\section{Abstract}

Ribeiro, Jarcélen Thaís Teixeira; Montaury, Alexandre. Irony as a strategy to relate: an investigation of Regresso Adiado by Manuel Rui. Rio de Janeiro, 2009. 65 p. MSc. dissertation - Departamento de Letras, Pontifícia Universidade Católica do Rio de Janeiro.

This research intends to analyze the literature production of the Angolan writer Manuel Rui, based on the writer's position regarding colonial relations between Portugal and Angola. Used as a resource which improves the comprehension of the author's writing, the concept of irony is also explored. Therefore, the intention of this work is to develop a research in such wise as to emphasize an aspect explored by the writer as a way to endorse its critical work. Assuming irony as a sense operator in his production, which figures in his tale book, published in 1974, this study is the result of an investigation based on the literary work produced during the many years of conflict before Angola's independence.

\section{Keywords}

Manuel Rui, Angolan literature, Portuguese colonialism, irony, the intellectual's function. 


\section{Sumário}

$\begin{array}{ll}\text { 1- Introdução } & 9\end{array}$

2 - Manuel Rui: uma pessoa contra

3 - Como explicar àquele colono um regresso adiado?

4 - Como é que um mulato pode ser de sangue azul?

21

5 - O aquário de Leonor

32

6 - Pensão custa caro

7 - Em tempo de guerra não se limpam armas

8 - Churrasco africano

54

9 - Conclusão

10- Referências Bibliográficas 
Mergulhar na história dos povos africanos é perceber a sucessão de impasses que enfrentaram e observar que, no conjunto das relações ali processadas, as cores da violência tingem o desenho da contradição que, é afinal, a marca essencial de sua existência. No palco da colonização, os confrontos entre dois universos culturais, entre dois modos de ver $e$ estar no mundo, foram constantes $e$ assumiram, muitas vezes, a forma de conflito.

Rita Chaves 